\title{
8
}

\section{COST-EFFECTIVENESS IN ANIMAL HEALTH}

\author{
An Ethical Analysis
}

\author{
Govind Persad
}

\begin{abstract}
Introduction
Many national health systems use cost-effectiveness information as part of determining which human health interventions to provide. The two most prominent cost-effectiveness metrics are quality-adjusted and disability-adjusted life-years (QALYs and DALYs, respectively), which typically are based on surveys of individuals' subjective experience of health setbacks. The ethicist Toby Ord has described consideration of cost-effectiveness as a "moral imperative," because replacing less costeffective treatments with more cost-effective ones can vastly increase the benefits a health system produces (Ord 2013). But other ethicists have criticized the use of cost-effectiveness information in priority-setting for giving no weight to distributional issues or making it more difficult for elderly and disabled individuals to receive health care interventions (Brock 2003). Some have attempted to reconcile these perspectives (John et al. 2017).

There is no similarly systematic discussion of the ethics of using cost-effectiveness information to set animal health priorities. ${ }^{1}$ This may once have reflected the difficulty of assessing animals' quality of life. But the increasing availability of quality-of-life information about animals indicates the value of parallel conceptual work on the ethics of using cost-effectiveness methods in animal health. One recent commentator observes that "[s]urprisingly, utility indices are not yet widely used in veterinary decision science or in veterinary practices," even though "quantification of disease burden could be very useful for decision making, priority setting and treatment comparisons in animal health care or simply to get an impression of the [quality of life] of the animal" (Pesie 2012).

This chapter evaluates the ethical issues that using cost-effectiveness considerations to set animal health priorities might present.in. Ultimately, its conclusions are cautiously optimistic. While using cost-effectiveness calculations in animal health is not without ethical pitfalls, these calculations offer a pathway toward more rigorous priority-setting efforts that allow money spent on animal well-being to do more good. Although assessing quality of life for animals may be more challenging than in humans, implementing prioritization based on cost-effectiveness is less ethically fraught.

In the first part, I review the current state of empirical measures of animal quality of life and consider the conceptual choices that underpin them, including philosophical disagreements about what quality of life amounts to and practical challenges in assessing the quality of life of creatures who cannot self-report their experiences using language. In the second part, I examine how ethical controversies presented by the use of cost-effectiveness information to set priorities for human health translate to the animal health context, such as conflicts between cost-effectiveness and individual
\end{abstract}




\section{Cost-Effectiveness in Animal Health}

rights. I also consider distinctive ethical challenges that the animal health context presents, in particular the problem of making cross-species comparisons of quality of life. In the third part, I consider different ways in which cost-effectiveness assessments could be used to set priorities and argue that doing so is both possible and desirable.

\section{Measuring Cost-Effectiveness in Animal Health}

Determining the cost-effectiveness of a health intervention involves assessing two different aspects of an intervention: (1) its cost and (2) its effects on length and quality of life. These two assessments are combined to produce a cost-effectiveness ratio. For instance, a course of cetuximab, a cancer treatment, costs US $\$ 80,000$ and improves overall survival in humans by 1.2 months, producing a cost-effectiveness ratio of more than $\$ 800,000$ per life-year (Fojo and Grady 2009).

Assessing the cost of animal health interventions is no more difficult than assessing the cost of similar interventions that improve human health. Assessments of the cost of veterinary medications and other animal health interventions are already frequently conducted as part of cost-effectiveness analyses of zoonotic diseases that affect human health (Schurer et al. 2015). Such assessments are also used in cost-benefit analyses that compare the cost of interventions that improve livestock health to the economic benefits ranchers derive from healthier livestock (Duarte et al. 2015). Likewise, the limitations that exist when assessing costs in human health-including the fact that sticker prices may not reflect costs from a societal perspective and that costs themselves are frequently reflective of societal determinations rather than being entirely independent of those determinations-apply to animal health (Persad 2016).

Cost-effectiveness analyses of zoonotic diseases, however, often entirely ignore how these diseasesand interventions to cure them-affect animals' quality of life. For example, echinococcosis, a zoonotic disease caused by a parasitic worm, can lead to serious illnesses not only in humans but also in host animals like sheep, dogs, and horses (Schurer et al. 2015). Animal health benefits from treating echinococcosis should also be part of the cost-effectiveness calculation. As Cass Sunstein has argued,

[o]n any plausible view, harm to animals matters, at least to some degree. This judgment is firmly reflected in American law. At the national level, the [Endangered Species Act] is complemented by the Animal Welfare Act, which is designed to protect a wide range of animals against suffering and premature death. Every state attempts to accomplish the same goal through anticruelty laws.

(Hsiung and Sunstein 2006: 1695)

It would be at least prima facie inconsistent with our willingness to spend money protecting the welfare of laboratory and farm animals to entirely ignore animal quality of life when considering how much to spend treating zoonotic diseases. More generally, if we are willing to give some weight to animal health, it makes sense to include animal health as an outcome in a cost-effectiveness analysis.

In order for cost-effectiveness analysis to incorporate both the costs and the health benefits of animal health interventions, we need an effective way of measuring how these interventions affect animal health. The most common metric for assessing the human health impact of a given intervention is the QALY. Determining QALY impact involves multiplying the number of years of life that the intervention provides by the quality of those years of life. In humans, comparative quality of life is assessed using "time trade-off" or "standard gamble" approaches, where people are asked to say what risk of death they would tolerate, or how much shorter a life they would accept, in order to avoid or eliminate a condition that impairs quality of life.

Because animals typically cannot respond to surveys, other strategies must be used to assess quality of life. A 2000 article in the Journal of the American Veterinary Medical Association summarizes research 
on quality-of-life measurement in animals. The article observes that quality of life in animals is typically assessed by having proxies, such as caregivers or medical professionals, complete surveys that elicit their beliefs about an animal's quality of life. The use of proxy surveys is not unique to animal health proxies are also used to assess quality of life for humans who are incapable of self-reporting their own quality of life, such as infants and those who are severely ill or disabled. Despite the limitation of proxy approaches, the article asserts that " $t$ the goal of measuring [quality of life] in animals from the perspective of the animals is not currently attainable" and that development of a proxy survey completed by humans offers the best chance of usefully measuring animal quality of life. Most of the more recent work on quality of life in animals relies on questionnaires completed by proxies (Belshaw et al. 2015; Mullan 2015).

What do these questionnaires ask? The questions asked, and the underlying definition of quality of life at issue, vary widely. A recent review article asserts that few studies of quality of life actually offer a definition of quality of life (Belshaw et al.2015). Most ask about perceived pain, and many ask about other topics such as function, sociability, and capacity to meet various needs. In general, these assessments have focused on the harms to quality of life that stem from disease, rather than considering how various capabilities might improve animals' quality of life.

Conceptual work on quality-of-life assessments in animals is likewise variable. The three most prominent philosophical accounts of quality of life in humans are the hedonic account, on which quality of life is a function of affective responses, the desire-fulfillment account, on which quality of life depends on the extent to which one's preferences are being fulfilled, and still others understand it via an objective list account, on which quality of life constitutes possessing objectively observable goods or capacities (Crisp 2016). Proxy questionnaires applying each of these approaches have been used for animal health. The hedonic approach is defended by one prominent commentator who contends that

assessment criteria, like the QOL [quality-of-life] factors they are intended to measure, have value only insofar as they are associated directly or indirectly with affective states. Measurement criteria that are not associated with affective states are not relevant to QOL and, hence, play no role in assessing QOL.

(McMillan 2000)

Other discussions propose using a desire-fulfillment account in which those answering questions evaluate how well an animal's preferences are being satisfied (Yeates 2016). One questionnaire proposes an objective list account, where respondents consider whether an animal enjoys various objective goods and capacities (Wojciechowska and Hewson 2005; Wojciechowska et al. 2005).

Is there any alternative to surveying humans about their perceptions of animals' quality of life? Franklin McMillan asserts that " $[\mathrm{t}]$ he goal of measuring QOL in animals from the perspective of the animals is not currently attainable" (McMillan 2000: 1908). Despite this claim that there is no alternative to human-completed questionnaires, some quality-of-life assessments for laboratory animals infer quality of life directly from behavior rather than soliciting the perspectives of human raters. Some have proposed that the "Mouse Grimace Scale," based on the idea that examining the facial expressions of mice could serve as an effective way of directly assessing whether mice are in pain (Matsumiya et al. 2012; Leach et al. 2012). Similarly, the ability of mice to perform certain tasks, or their aversive behavior when faced with a stimulus, could be regarded either as indicators of quality of life or as constituents of quality of life (Urban et al. 2011). The strategy of assessing quality of life based on direct observations of behavior could potentially be applied not only to mice but also to companion animals and livestock. As another example, one article proposes looking at hormonal and physiological changes, such as changes in heart rate or hormone concentration (Stockman et al. 2011; Christiansen et al. 2007). 
For any of these assessment techniques, it is important to keep in view the fact that whatever is being measured must be matter in order to be worth measuring in the first place. Some approaches may provide plentiful and easily accessible quantitative data, but that data may not represent any aspect of animals' lives that is morally significant. Even if perfect consensus cannot be reached on what is morally significant in animal quality of life, however, the strategies presented earlier represent potentially effective ways of assessing quality of life in various animals.

\section{Translating Current Issues in the Ethics of Cost-Effectiveness to Animal Ethics}

Quality of life determinations could potentially be used for a variety of purposes, including deciding what sort of clinical care an animal needs, punishing those who cause unjustified pain or injury to animals, or designing zoos, farms, and other types of spaces where animals live. My focus, however, is the use of quality-of-life assessments as part of priority-setting. Quality-of-life assessments are frequently used, in combination with costs, to generate cost-effectiveness figures that are then used to set priorities for human health. For instance, the health care system in the UK uses quality-of-life assessments to determine which interventions fall within a cost-effectiveness threshold (Drummond and Sorenson 2009). They have also been proposed for use in other contexts, such as setting comparative priorities between health care and public health, determining which services are provided in markets or paid for by private insurers, and indicating which interventions should be high priorities for research (Graham et al. 1998; Clement et al. 2009; Persad 2016).

In this section, I consider how several ethical challenges that cost-effectiveness methodologies face when used to set human health priorities might translate to the animal health context. These include the challenges of comparing quality of life across different conditions; of avoiding violations of rights; and of treating people with disabilities or short life expectancies fairly. I also consider a challenge that has special resonance in the animal ethics context: cross-species comparison of quality of life.

\section{Quality of Life Across Conditions}

One challenge that is magnified in the animal health context involves the commensurability of quality-of-life measures across conditions. Some argue that it is difficult to compare the quality of life impacts of different medical conditions, such as limited mobility and chronic pain. It may be even harder to compare quality of life across different animals or animal species.

One possibility, if we use the questionnaire approach, is to ask humans these questions on behalf of the animals they are responsible for. This presents a variety of problems. First, humans who are responsible for animals may answer the questions in light of their own moral obligations to animals, obligations that may not track what is good for the animal overall. They may also select outcomes that are better for human caretakers even though worse for animals. For instance, humans may regard outcomes where an animal dies quickly as preferable to outcomes where an animal suffers in pain under their supervision, even if the animal would, in fact, be better off under the second option. Second, moving from the deontic (what decision makers should do) to the axiological (what is valuable), proxy decision makers may, in general, judge outcomes to be different from the way that they seem from the first-person perspective. For instance, people typically prefer pains to be in their own past rather than in their own future but may not exhibit the same time bias when they consider the pains that others experience (Dorsey 2016). Third, human survey respondents may simply lack knowledge of what is actually in the interest of the animals whose lives they are describing.

One alternative would be to ascertain quality-of-life judgments by looking at the risks and tradeoffs animals actually accept—-for instance, the risks they are willing to take in order to avoid pathogens 
or to engage in play activities. We could regard animals' actual behavior as revealing a preference for certain health states over others. However, some might worry that these revealed preferences are hard to interpret. It is difficult to tell whether a given decision reflects a general preference or just a preference in a particular context. It is also challenging to know the extent to which we should try to determine what is good for animals by looking at what they actually do. For instance, the fact that dogs are willing to drink out of toilets might seem to suggest that they are willing to tolerate a high risk of illness in order to pursue their goal. But we might instead conclude that dogs, left to their own devices, are mistaken about what, in fact, is in their own interest. (They are like the person in John Stuart Mill's famous example who is about to cross a rickety bridge he does not realize is rickety.) Similarly, some have argued that the fact that animals often hide when they notice a photographer suggests that they value privacy in the way that humans do and that hidden cameras would set back animal privacy interests just as they set back human ones (Pepper, unpublished). But their decision to hide might reflect a mistake about the photographer's purposes or about what the photographer is holding. This would push us toward an account of animal quality of life that is based on idealized choices (see Heathwood 2006) or instead toward an account that is based on objective experiences or on measurements of hedonic states.

Particularly in the case of dogs and other social or altruistic animals, a further complication of a revealed preference approach is that not all an individual's choices aim to improve that individual's own quality of life. As an example, Amartya Sen argues that we should recognize that individuals sometimes make choices in full knowledge that those choices will worsen their own quality of life in order to honor certain commitments that they have (Sen 1977). The soldier who throws himself on a grenade to save his platoon does not thereby reveal that he judges being pulverized to be an improvement in his quality of life. Rather, he sacrifices his quality of life in order to honor his commitment to his fellow soldiers. This is true for animals as well: various choices animals might make could be understood not to aim at improving their quality of life but, rather, at honoring their commitments. These commitments can be to conspecifics, such as cases where animals sacrifice their lives for fellow pack members, but cross-species commitments are also possible (Casal 2012). Another concern involves what Jon Elster, Sen, and Martha Nussbaum have dubbed "adaptive preferences" (Teschl and Comim 2005). Animals may elect to do various things not because they contribute either to their own quality of life or to their commitments but, rather, because have been led to act in ways that serve the interests of others because of a mistaken sense of self-worth.

These concerns about purely desire-based approaches suggest the attractiveness of either hedonic or objective-list measures of animal quality of life that allow for comparisons across different conditions. Given the complexity of many animals' lives, I would argue that the same considerations that favor objective-list measures over purely hedonic ones-namely, that more matters to people than merely their psychological states-also apply to many animals.

One possibility is to use an externally observed hedonic account of quality of life to assess quality of life in animals that lack sophisticated self-awareness and long-term planning but to use an objective-list account (developed primarily through observation but also potentially through questionnaires) to assess quality of life among more mentally sophisticated animals. This distinction might track David DeGrazia's suggestion that the interests of fish, amphibians, reptiles, and birds be assigned different, and lower, priority than the interests of other sentient animals (DeGrazia 1996). On this view, some animals are capable of having a rich quality of life that goes beyond purely hedonic reactions while others are not.

\section{Quality of Life and Rights}

Another challenge involves tensions between the utilitarian bent of most cost-effectiveness approaches and respect for individual rights. The 1991 Oregon Medicaid proposal, which set priorities strictly on 


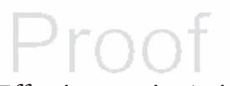

Cost-Effectiveness in Animal Health

the basis of cost-effectiveness, was criticized for providing cost-effective but low-urgency interventions, such as tooth capping, in preference to urgent but costly interventions such as appendectomies (Hadorn 1991). This objection involves what philosophers call the aggregation problem-whether many minor burdens can be aggregated to outweigh a major burden. A related objection, termed the fair chances/best outcomes problem, questions the exclusion of individuals who are unlikely to benefit, and a third, termed the separate spheres/indirect benefits problem, contends that cost-effectiveness approaches give excessive weight to whether individuals who receive interventions will, in turn, produce other benefits for society (Daniels 1993).

Many have suggested that utilitarian reasoning is distinctively appropriate when only animal interests are at issue (McMahan 2002; Nozick 1983). ${ }^{2}$ Jeff McMahan effectively summarizes this view when he states that the "morality of respect," which includes nonconsequentialist rights, applies to persons, but the "morality of interests," which does not, applies to sentient animals (McMahan 2002). If this is correct, cost-effectiveness methodologies might face fewer ethical headwinds when used to set priorities in animal health than they do in human health. It might be appropriate to, for instance, prevent many pigs from suffering painful bruises than to prevent a single pig from suffering very severe pain, even if it is inappropriate to make similar calculations where the lives of beings who fall within the morality of respect are at issue. It may also be appropriate to invest no resources at all in curing certain very rare animal diseases if those resources could instead be used to cure much more common diseases. In fact, even more radical utilitarian decisions that are widely agreed to be inappropriate in human health might be appropriate where animals are concerned, such as killing some animals in order to prevent a disease from spreading to many more.

McMahan's view is well argued for and seems normatively plausible. If adopted, it would broaden the scope of permissible use of cost-effectiveness measures in animal health. However, others suggest that animals should be accorded deontological rights rather than being regarded as mere subjects of interests (Regan 1985) or that "it's not in general permissible to cause serious pain and injury to one morally significant entity," including an animal, "in order to benefit others" (Harman 2011). If animals fall within what might be termed the morality of respect, then rights-based concerns about the use of cost-effectiveness criteria to set priorities have more traction. A rights-based view also coheres with some of our practices regarding animals - in particular, the view in animal research that prioritizes refining research over reducing number of animals used on the basis that "the experience of an individual animal is paramount to the number of animals, and that additional suffering for the individual in exchange for a reduced total number of animals is not acceptable" (Boo et al. 2005; see also Ringblom 2016). This echoes the deontological view in human bioethics that recommends saving one person from death over saving many from minor pain.

However, many uses of cost-effectiveness criteria do not conflict with conventionally recognized rights, because they move resources toward more cost-effective uses without violating any rights (Ord 2013). In order to resist these uses of cost-effectiveness criteria, one would have to assign moral weight to much more controversial rights claims, such as the "rule of rescue," which recommends favoring identifiable lives over statistical lives or the view that numbers should not count when aid is being provided (see Persad 2019b).

An intermediate possibility is also interesting. On this view, the appropriateness of utilitarian reasoning in animal health would depend on the relevant animals' capacities and social organization: this suggestion builds on Judith Thomson's speculation that act-utilitarianism is appropriate for eusocial animals but inappropriate for humans (Thomson 1990). Utilitarianism might similarly be inappropriate for animals who are relevantly similar to humans but appropriate for social animals. By this logic, we might use a highly nonconsequentialist ethical theory for balancing the interests of animals that are solitary and typically competitive with conspecifics, such as tigers, in one way; a moderately nonconsequentialist theory for balancing the interests of animals who (like humans) are limited altruists in another way; and a utilitarian theory for balancing the interests of eusocial animals 
like bees. While this way of developing Thomson's view is interesting, it has two clear limitations. One is that it may base moral obligations and permissions too closely on the natural abilities of specific creatures: that tigers may sometimes attack other tigers in nature does not entail that we should regard their interests as highly separate from a moral point of view. Another is that it does not address the question of how to handle trade-offs between the interests of animals from different species.

\section{Quality of Life and Individual Differences}

Cost-effectiveness approaches have been criticized for disadvantaging individuals who, because of comorbidities, can gain less quality or quantity of life from treatment. As an example, some costeffectiveness approaches to priority setting would assign lower priority for curing the cancer of someone who is blind, because the future life they gain from the treatment will be lower in quality due to their disability. This outcome has been criticized for being unjust and for further disadvantaging the already disadvantaged (Menzel et al. 1999; see also Persad 2019a). Another example is that most cost-effectiveness approaches will also assign lower priority to curing an illness for someone who cannot live for many more years, as opposed to someone who can live for many more years. John Harris and others have argued that this approach unfairly ignores the equal moral worth of each individual (Harris 1987).

The frequently held view that extending animals' lives matters much less from a moral point of view than does improving their quality of life would simplify the latter problem. If additional lifeyears are assigned little or no value but quality of life has very high value, then animals who can potentially live for a longer time if they receive health benefits will receive little additional priority. However, the view that additional life counts for nothing seems implausible: we are willing to perform painful surgeries on some animals rather than painlessly euthanizing them, and we do so, in part, because we regard quantity, not only quality, of life as valuable for animals. Elizabeth Harman (2011) illustrates this through a case of a young cat undergoing surgery (see also DeGrazia 2016). Nonetheless, even though quantity of life in animals seems to count for something, it is plausible that quantity of life counts for less where animals are concerned. This suggests, for animals, replacing the standard way of calculating the QALY with a different function in which quantity is reduced in importance.

The problem of fairness to individuals with different capacities, in contrast, remains similarly urgent in the animal health context, and perhaps even more urgent given the differences between species. Imagine that wild turkeys have a better quality of life than chickens but the same moral status. Should we be more interested in extending the life of the animal that starts out having a greater quality of life, or should we treat animals of equal moral status equally even if they differ in capacity? (Differences in moral status form a different, and potentially orthogonal, basis for prioritizing some animals over others.) The answer to this question depends on whether there is a way of comparing quality of life across species, a question I take up in the next section. But similar questions can arise even regarding intraspecies decision making — should we assign lower priority to extending the life of a permanently blind horse than a healthy one? Again, the answer to these questions seems to depend in part on whether we regard animals as being within the morality of respect or instead within a morality of interests.

\section{Quality of Life Across Species}

Priority setting for animal health can be done with a wider or a narrower focus. Narrow priority setting would determine which interventions are of highest priority for a specific, homogeneous population - for instance, which chicken coop designs are most cost-effective at improving chickens' 
quality of life. Broader priority setting would attempt to set priorities among wider groups, including multiple species - for instance, to determine which alignment for a train line through a green space would least reduce the quality of life of the animals living in the green space or what treatment for animal disease should be the highest priority for a laboratory that is researching many animal diseases.

Wide priority setting in animal health presents the problem of cross-species comparisons. For instance, the green space example might involve considering how various harms caused by pollution or noise affect the quality of life of deer, marmots, bears, and migratory birds. More challenging, they might also involve comparing the relative importance of a given change in quality of life for one type of animal to the importance of that change for other animals. We typically assume that all humans' quality of life interests are given the same moral weight when setting priorities using cost-effectiveness considerations (Drummond and Sorenson 2009). But this conclusion is much less obvious when we are making cross-species comparisons. It might seem mistaken, for instance, to assign the same weight to the loss in quality of life that a salamander would experience as to the loss that a bear or wolf would experience. However, determining what weight to assign to each individual's experiences is challenging. There is no obvious time trade-off or standard gamble-or revealed preference analogue of these- that would compare whether it is better to be a wolf or a salamander. Wolves and salamanders do not face situations where they could become members of the other species. Nor are there "competent judges," in John Stuart Mill's terms (see Brownlee 2016) who have lived both sorts of lives and could recommend which is better.

One response to the challenge of cross-species quality of life comparisons would be to retreat to an approach that offers only a partial ordering of priorities (Ruger 2004): on this approach, costeffectiveness could be used to set priorities within species but not between species. David DeGrazia seems to favor such a view in his comments on the potential incommensurability of human and animal quality of life:

[Consider the assumption] that there is a sort of objective super-scale of prudential value, by reference to which one can evaluate the well-being of every actual and possible creature in virtue of its realization of the items enumerated on the massive (infinite?) list. One might find, as I do, the sheer grandiosity of such a conception a reason to doubt it. It seems to require a standpoint of prudential evaluation that is so impartial as to be God-like, or Platonic Form-like.... Despite lacking a decisive argument against the idea of an objective super-scale of prudential value, I suspect that this idea is misguided. It seems to me more plausible that assessments of prudential value must be relativized to the sort of creature in question and, in particular, to the native capacities of such creatures.

(DeGrazia 2016: 514-515)

However, the frequent skepticism in animal ethics about the fundamental moral weight of biological categories such as species membership (McMahan 2002), and the potential value of an approach that assists decisionmakers who must compare the interests of different types of animals-ranging from veterinarians conducting triage and allocating limited treatments to policymakers setting priorities for animal health investments-indicates the value of a quality-of-life measure that crosses species boundaries.

What are the candidates for such a measure? As discussed earlier, the most natural ones are objective-list measures (either conducted by proxies or external assessment) and hedonic measures. As DeGrazia observes, of course, there are challenges in constructing an objective list measure. To riff on Mill, is it better to be a "salamander satisfied" or a "pig dissatisfied"? Even if we can determine, for example, that it is worse to be a pig in chronic pain than a pig with a hearing impairment, it is hard to identify the list of capacities that would tell us whether it is better to be a pig in chronic pain or 
a healthy salamander. Notwithstanding these challenges, however, generating broader quality-of-life assessments seems possible. As McMahan observes,

[i]t might be suggested that individuals should be ranked hierarchically according to their level of psychological capacity or potential. On this view, all individuals with equivalent capacities or potential would count as higher forms of being than individuals with lower capacities and potential. This offers a way of articulating our sense that it is better to be a person than to be a dog. Persons are higher forms of being: their capacities are higher, the range of good accessible to them is higher, and in general their lives are better, or more valuable, or more worth living, than those of dogs

(McMahan 2002: 160).

DeGrazia, in discussing similar cases, expresses skepticism about the specific judgment that dogs are better off than human persons, although he does not categorically reject the view. He observes that "[n]o human being has had, for example, the experience of walking through the neighborhood and recognizing the unmistakable scents of dozens of familiar people and dogs. No human being has experienced the magnificent depths of auditory experience that dogs experience every day" (DeGrazia 1996: 4). As a factual matter, DeGrazia is correct. But it seems plausible that the value of complex psychological experiences, such as composing a symphony or designing a fragrance outweighs the value of the sensory experience of smelling many fragrances or hearing many sounds, particularly from an objective-list rather than purely hedonistic perspective. (Think of Beethoven even after his deafness.) DeGrazia himself grants that he lacks a decisive argument against "an objective super-scale of prudential value" (DeGrazia 1996: 4), and the use of such a scale has the advantage that it avoids regarding species membership itself as objectively significant. ${ }^{3}$

In any event, DeGrazia's relativization approach appears too strong-it forecloses the possibility of plausible partial orderings across different types of creatures. Even if one agrees with DeGrazia that the experience of animals like dogs, dolphins, and bats is so different from humans' experience of living their lives as to be incommensurable, there may be some species of animals whose life experiences are "strictly dominated" (to use technical language) by the experiences of other, similar animals - their capacities are close to a proper subset of other animals' capacities. An example might be dolphin species that are less intelligent than the bottlenose dolphin but have the same sensory capacities; more broadly, we might be able to compare very different species of birds and conclude that some have richer lives than others. We might also be able to compare different developmental stages or morphological forms of the same organism: even though tadpoles have some capacities that frogs lack, it seems plausible that frogs overall have a richer set of experiences.

A different way of approaching the problem of cross-species comparisons is to focus on communities of animals or on ecosystems, rather than on the effects of policy decisions or other forces on individual animals. This approach would combine the interests of all animal denizens of the park (as well as potentially other living beings, and even the interests of natural artifacts insofar as they can be said to have interests), and would then assess the impact of the choice on the interests of the ecosystem as a whole. This approach would clearly reject the position taken by thinkers such as Regan and Harman, who regard each individual as separate and worthy of respect, in favor of a more holistic evaluation of the ecosystem's good. However, it would also differ from the position that McMahan defends, which regards the quality of life that different animals enjoy as commensurable. Instead of comparing different animals' quality of life, it would subsume their experiences under a larger unit of evaluation.

Last, reasoning about moral status may pull in a different direction from reasoning about quality of life. We might conclude, based on an objective list of capacities such as complex planning, complexity, and community living, that it is preferable to be a pig than to be a salamander, and even that it is better to be a pig in chronic pain than to be a salamander in good health. (This is what we 
conclude about the comparison between humans and salamanders.) Yet we may conclude that it is more morally urgent to relieve the pain of a pig than that of a salamander, even though it may be far worse to be a salamander in ill health than a pig in ill health. DeGrazia discusses, although does not explicitly endorse, an "unequal consideration" account of moral status that incorporates not only the capacities an animal has but also what sort of considerability the animal possesses (DeGrazia 2008). Cost-effectiveness approaches could operationalize DeGrazia's unequal consideration account by differentially weighting quality-adjusted life-years or similar metrics according to the moral status of the animal whose health is at issue.

Another factor that could be relevant, and could pull in a different direction from quality of life, is the special obligations that may be owed to certain animals or groups of animals. Recent work by Sue Donaldson and Will Kymlicka makes the case that domesticated animals are owed obligations of co-citizenship, whereas wild animals should instead be afforded sovereignty, and "liminal" animals, which live in human communities but are not domesticated, should be granted a "denizenship" status that differs from citizenship (Donaldson and Kymlicka 2011). Importantly, Donaldson and Kymlicka's approach does not base special obligations on animals' capacities or quality of life- as an example, rabbits could be owed obligations of co-citizenship, sovereignty, or denizenship depending on whether they are pet rabbits, wild rabbits, or rabbits living in proximity to humans. Ultimately, quality of life is unlikely to be the only factor in cross-species priority setting and can be outweighed by considerations of moral status or special obligation.

\section{Operationalizing Cost-Effectiveness to Set Priorities in Animal Health}

Perhaps the simplest and least controversial strategy for expanding the use of cost-effectiveness in animal health is to use quality of life measures to create species-specific QALY analogues. One such example could be, for instance, QADYs (quality-adjusted dog years). This approach would not take on the challenge of making cross-species comparisons but could be used to set priorities for research into medical interventions that might benefit dogs or to decide which dogs should receive a scarce medical resource in a triage situation.

A more controversial approach would be to try to find some way of commensurating the speciesspecific metrics into a unified metric. We might call this the QAALY (quality-adjusted animal lifeyear). ${ }^{4}$ Using a QAALY distributive metric would allow priorities to be set for interventions that affect many different species of animal—for instance, whether to prioritize a given treatment for pigs over another one for chickens.

Even without a QAALY distributive metric in place, it may still be possible to make some prioritysetting decisions in light of species-specific quality-of-life measures. This could involve a process of weighing, specifying, and balancing different considerations against one another, just as is done when QALYs are being compared to non-QALY criteria in human health contexts. It could also involve the use of an extended cost-effectiveness analysis that compares costs to both quality-of-life outcomes and other types of outcomes (see Garrison et al. 2017).

One challenging issue for both QAALYs and the species-specific approach involves potential conflicts between human and animal interests. Would we ever be justified in preferring to realize some quantity of animal QALYs rather than a smaller quantity of QALYs for humans? This may seem intolerable where life and death for humans are considered and may favor a "lexical priority" approach in which the lives of humans are incomparably more important than quality improvements in the lives of animals, no matter how many animals benefit (see Zamir 2006: n.3). On the other hand, commonsense practice does allow some trade-offs between human and animal QALYs where human life is not directly at stake, particularly when the amount of human suffering at issue is small-for instance, we might accept a slightly more painful treatment for humans if it can be produced in a way that causes less animal pain (Zamir 2006). 
When combined with the common view that some cases of human pain are more morally significant than some risks to human life-which underlies, for instance, the permissibility of risky surgery to cure chronic pain - this could present a problem of intransitivity: a sufficient quantity of human pain can be more important than a human life, but no quantity of animal pain could justify sacrificing a human life, yet some quantity of animal pain could outweigh a quantity of human pain. Similar intransitivities are familiar elsewhere in bioethics (Kamm 1985).

\section{Conclusion}

I have argued in favor of greater use of cost-effectiveness criteria to set priorities in animal health. I close with a practical note of caution: a familiar challenge to priority setting discussed by Norman Daniels retains force and relevance in the animal ethics context. Daniels argues that it is difficult to justify comprehensively setting priorities for medical interventions using cost-effectiveness calculations within a health care system, like that in the US, where the savings realized by reducing the provision of interventions with poor cost-effectiveness will not necessarily go toward the provision of more cost-effective interventions, which would lead to net improvements in health but might instead go toward nonhealth programs (Daniels 1986). Some might similarly worry that prioritysetting efforts will lead to less money being spent on worthy goals in animal health, and redirected toward other, less important, aims. For priority setting that cuts spending on animal health, rather than reallocating it, to be justified, the alternative spending proposal must be more important.

Notwithstanding Daniels's concerns, incorporating cost-effectiveness considerations into choices regarding animal health could lead to substantial improvements in animal health. Many of the ethical constraints that count against the use of cost-effectiveness to set priorities do not apply, or at least not so clearly, to their use in setting priorities among animals and with regard to animal health issues. Yet there is little current use of cost-effectiveness to set priorities in animal health-much less than in human health. This perhaps stems from the fact that animal health is highly disunified, with care for wild animals, farm animals, pets, and laboratory animals governed by different rules and policies. There is no National Health Service or Medicaid for animals, or National Institutes of Health to organize research into animal health. Yet we spend substantial sums of money on animal health despite this and do so in a disorganized way. As an example, federal law in the US requires that pets be included in emergency planning (Leonard and Scammon 2007). Many millions of dollars are spent on animal health. Even if some of this spending has the goal of promoting human interests, some of it is clearly spent on animals themselves. By considering cost-effectiveness, we can use that money to make animals' lives go better. As Ord observes in human health contexts, "[i]gnoring costeffectiveness ... does not mean losing 10 percent or 20 percent of the potential value that a health budget could have achieved, but can easily mean losing 99 percent or more" (Ord 2013: 5). He goes on to state that " $[\mathrm{t}]$ he main effect of understanding the moral imperative toward cost-effectiveness is spending our budgets so as to produce greater health benefits, saving many more lives and preventing or treating more disabling conditions" (Ord 2013: 7). This is true for humans, but it is at least as true for animals. It is time to consider cost-effectiveness in animal health.

\section{Notes}

1. I use animal as shorthand throughout for "nonhuman animal."

2. Elizabeth Harman presents but rejects the view that "[o]ne might try to develop a view on which the kinds of agent-relative constraints that apply to persons do not apply to animals or animal stages. On such a view, it would be permissible to harm one animal or animal stage in order to provide positive benefits to a distinct entity," without discussing McMahan's view on the morality of respect, even though she discusses other parts of McMahan's book (Harman 2011). 


\section{Cost-Effectiveness in Animal Health}

3. "But while it seems right that a condition must be evaluated by comparison with what is possible given a certain set of psychological capacities, it seems a mistake to suppose that the relevant capacities are those typical of the members of the individual's own biological species" (McMahan 2002: 325).

4. Pesie similarly suggests that " $[\mathrm{t}]$ his research explores the possibilities to develop an Animal Health Utility Index (AHUI), by which reductions in QoL can be quantified to indicate the 'Animal Disease Burden' (ADB) (i.e. the change in QoL during a time period), comparable to the quantification of QALYs in humans" (Pesie 2012: note 4).

\section{References}

Belshaw, Z., Asher, L., Harvey, N., and Dean, R. (2015) "Quality of life assessment in domestic dogs: An evidencebased rapid review," The Veterinary Journal 206(2): 203-212.

Boo, J., Rennie, A., Buchanan-Smith, H., and Hendriksen, C. (2005) "The interplay between replacement, reduction and refinement: Considerations where the three Rs interact," Animal Welfare 14(4): 327-332.

Brock, D. (2003) "Ethical issues in the use of cost-effectiveness analysis for the prioritization of health care resources," in T. T. T. Edejer, R. Baltussen, T. Adam et al. (eds.) WHO Guide to Cost-Effectiveness Analysis (pp. 289-312), Geneva, Switzerland: World Health Organization, www.who.int/choice/publications/p_2003_ generalised_cea.pdf (Accessed March 19, 2019).

Brownlee, K. (2016) “The competent judge problem,” Ratio 29(3): 312-326.

Casal, P. (2012) "Sexual dimorphism and human enhancement," Journal of Medical Ethics 39(12): 722-728.

Christiansen, S., Billeschou, S., and Forkman, B. (2007) "Assessment of animal welfare in a veterinary contexta call for ethologists," Applied Animal Behavior Science 106(4): 203-220.

Clement, F., Harris, A., Li, J., Yong, K., Lee, K., and Manns, B. (2009) "Using effectiveness and cost-effectiveness to make drug coverage decisions: A comparison of Britain, Australia, and Canada," JAMA 302(13): $1437-1443$.

Crisp, R. (2016) “Well-being,” in E. Zalta (ed.) The Stanford Encyclopedia of Philosophy, [online] Summer, https:// plato.stanford.edu/entries/well-being/\#TheWelBei (Accessed March 20,2019).

Daniels, N. (1986) "Why saying no to patients in the United States is so hard: Cost containment, justice, and provider autonomy," New England Journal of Medicine 314(21): 1380-1383.

Daniels, N. (1993) "Rationing fairly: Programmatic considerations," Bioethics 7(2-3): 224-233.

DeGrazia, D. (1996) Taking Animals Seriously: Mental Life and Moral Status (p. 280), New York: University of Cambridge.

DeGrazia, D. (2008) “Moral status as a matter of degree?” The Southern Journal of Philosophy 46(2): 181-198.

DeGrazia, D. (2016) "Sentient nonpersons and the disvalue of death," Bioethics 30(7): 511-519.

Donaldson, S., and Kymlicka, W. (2011) Zoopolis: A Political Theory of Animal Rights, New York: Oxford University Press.

Dorsey, D. (2016) “Future-bias: A (Qualified) defense,” Pacific Philosophical Quarterly 98(S1): 317-344.

Drummond, M., and Sorenson, C. (2009) "Nasty or nice? A perspective on the use of health technology assessment in the United Kingdom," Value in Health 12(2): S8-S13.

Duarte, C., Freitas, P., and Bexiga, R. (2015) “Technological advances in bovine mastitis diagnosis: An overview," Journal of Veterinary Diagnostic Investigation, [online] 27(6): 665-672. https://doi.org/10.1177/104063871 5603087 (Accessed March 19, 2019).

Fojo, T., and Grady, C. (2009) "How much is life worth: Cetuximab, non- small cell Lung Cancer, and the $\$ 440$ billion question," JNCI Journal of the National Cancer Institute, [online] 101(15): 1044-1048. https://doi. org/10.1093/jnci/djp177 (Accessed March 19, 2019).

Garrison, L., Kamal-Bahl, S., and Towse, A. (2017) “Toward a broader concept of value: Identifying and defining elements for an expanded cost-effectiveness analysis," Value in Health 20(2): 213-216.

Graham, J., Corso, P., Morris, J., Segui-Gomez, M., and Weinstein, M. (1998) "Evaluating the cost-effectiveness of clinical and public health measures," Annual Review of Public Health 19(1): 125-152.

Hadorn, D. (1991) “Setting health care priorities in Oregon: Cost-effectiveness meets the rule of rescue," JAMA 265(17): 2218-2225.

Harman, E. (2011) “The moral significance of animal pain and animal death," in T. Beauchamp and R. Frey (eds.) The Oxford Handbook of Animal Ethics (pp. 726-737), Oxford: Oxford University Press.

Harris, J. (1987) "QALYfying the value of life," Journal of Medical Ethics 13(3): 117-123.

Heathwood, C. (2006) "Desire satisfactionism and hedonism," Philosophical Studies 128(3): 539-563.

Hsiung, W., and Sunstein, C. (2006) “Climate change and animals,” University of Pennsylvania Law Review, [online] 155(6): 1695, https://scholarship.law.upenn.edu/penn_law_review/vol155/iss6/7 (Accessed March 19, 2019). 
John, T., Millum, J., and Wasserman, D. (2017) "How to allocate scarce health resources without discriminating against people with disabilities," Economics and Philosophy 33(2): 161-186.

Kamm, F. (1985) "Supererogation and obligation," The Journal of Philosophy 82(3): 118-138.

Leach, M., Klaus, K., Miller, A., Di Perrotolo, M., Sotocinal, S., and Flecknell, P. (2012) “The assessment of postvasectomy pain in mice using behaviour and the mouse grimace scale," PLoS Medicine 7(4).

Leonard, H., and Scammon, D. (2007) “No pet left behind: Accommodating pets in emergency planning," Journal of Public Policy \& Marketing 26(1): 49-53.

Matsumiya, L., Sorge, R., Sotocinal, S., Tabaka, J., Wieskopf, J., Zaloum, A., King, O., and Mogil, J. (2012) "Using the mouse grimace scale to reevaluate the efficacy of postoperative analgesics in laboratory mice," Journal of the American Association for Laboratory Animal Science 51(1): 42-49.

McMahan, J. (2002) The Ethics of Killing: Problems at the Margins of Life, New York: Oxford University Press.

McMillan, F. (2000) "Quality of life in animals," Journal of the American Veterinary Medical Association 216(12): 1904-1910.

Menzel, P., Gold, M., Nord, E., Pinto-Prades, J., Richardson, J., and Ubel, P. (1999) "Toward a broader view of values in cost-effectiveness analysis of health," Hastings Center Report 29(3): 7-15.

Mullan, S. (2015) “Assessment of quality of life in veterinary practice: Developing tools for companion animal carers and veterinarians," Veterinary Medicine: Research and Reports 6: 203-210.

Nozick, R. (1983) “About mammals and people,” New York Times Book Review, November 27, pp. 11, 29-30.

Ord, T. (2013) The Moral Imperative toward Cost-Effectiveness in Global Health [online], Center for Global Development, p. 7, www.cgdev.org/publication/moral-imperative-toward-cost-effectiveness-global-health (Accessed March 19, 2019).

Persad, G. (2016) “Should research ethics encourage the production of cost-effective interventions?” in D. Strech and M. Mertz (eds.) Ethics and Governance of Biomedical Research: Theory and Practice, Switzerland: Springer.

Persad, G. (2019a) "Considering quality of life while repudiating disability injustice: The pathways approach to priority-setting," The Journal of Law, Medicine, and Ethics 47(2): 294-303.

Persad, G. (2019b) "Will more organs save more lives? Cost-effectiveness and the ethics of expanding organ procurement," Bioethics 33(6): 684-690.

Pesie, S. (2012) Quantification of Animal Disease Burden; Exploring the Possibilities of a Dog-Health Utility Index, MSc thesis, Wageningen University, http://edepot.wur.nl/244416 (Accessed March 19, 2019).

Regan, T. (1985) “The case for animal rights," in P. Singer (ed.) In Defense of Animals, Oxford: Basil Blackwell.

Ringblom, J. (2016) Worth Weighting For-Studies on Benchmark Dose Analysis in Relation to Animal Ethics in Toxicity Testing, PhD Karolinska Institutet, pp. 11-14, https://openarchive.ki.se/xmlui/bitstream/handle/ 10616/45331/Thesis_Joakim_Ringblom.pdf?sequence=1\&isAllowed=y (Accessed March 19, 2019).

Ruger, J. (2004) "Health and social justice," Lancet 364(9439): 1075.

Schurer, J., Rafferty, E., Farag, M., Zeng, W., and Jenkins, E. (2015) "Echinococcosis: An economic evaluation of a veterinary public health intervention in rural Canada," PLoS Neglected Tropical Diseases, [online] 9(7): e0003883. https://doi.org/10.1371/journal.pntd.0003883 (Accessed March 19, 2019).

Sen, A. (1977) "Rational fools: A critique of the behavioral foundations of economic theory," Philosophy \& Public Affairs 6(4): 317-344.

Stockman, C., Collins, T., Barnes, A., Miller, D., Wickham, S., Beatty, D., Blache, D., Wemelsfelder, F., and Fleming, P. (2011) "Qualitative behavioural assessment and quantitative physiological measurement of cattle naïve and habituated to road transport," Animal Production Science 51(3): 240-249.

Teschl, M., and Comim, F. (2005) "Adaptive preferences and capabilities: Some preliminary conceptual explorations," Review of Social Economy 63(2): 229-247.

Thomson, J. (1990) The Realm of Rights, Cambridge: Harvard University Press.

Urban, R., Scherrer, G., Goulding, E., Tecott, L., and Basbaum, A. (2011) "Behavioral indices of ongoing pain are largely unchanged in male mice with tissue or nerve injury-induced mechanical hypersensitivity," Pain 152(5): 990-1000.

Wojciechowska, J., and Hewson, C. (2005) "Quality-of-life assessment in pet dogs," Journal of the American Veterinary Medical Association 226(5): 722-728.

Wojciechowska, J., Hewson, C., Stryhn, H., Guy, N., Patronek, G., and Timmons, V. (2005) "Development of a discriminative questionnaire to assess nonphysical aspects of quality of life of dogs," American Journal of Veterinary Research 66(8): 1453-1460.

Yeates, J. (2016) “Quality of life and animal behavior," Applied Animal Behaviour Science 181: 19-26.

Zamir, T. (2006) "Killing for knowledge," Journal of Applied Philosophy 23(1): 17-40. 